\title{
Geographic epidemiology of medullary thyroid cancer families: unearthing European ancestral heritage
}

\section{Dear Editor,}

Some 50 years ago, astute clinicians identified a familial medullary thyroid cancer (MTC) syndrome associated with pheochromocytoma and/or pseudonodular parathyroid hyperplasia. These hereditary conditions now are subsumed under the umbrella term of multiple endocrine neoplasia type 2A or MEN 2A (Wells et al. 2015). The genetic cause of MEN 2A was identified in the 1990s: missense mutations in the rearranged during transfection (RET) proto-oncogene on chromosome 10q11.2, encoding the RET transmembrane tyrosine kinase receptor. This seminal discovery offered unprecedented insights, beyond genotype-phenotype correlations (Eng et al. 1996, Machens et al. 2013a), into the molecular epidemiology of MEN 2A (Machens et al. 2009, 2013b, Romei et al. 2010).

Recent ethnographic fieldwork and haplotype analysis, published in 2016 and 2017, traced founder mutations RET p.M918V and p.G533C from Brazil back to the Iberian Peninsula, identifying:

- A p.M918V ancestor from Portugal (city of Braga) who migrated to Northeastern Brazil (state of Ceará) in the 1600s (Martins-Costa et al. 2016);

- A p.G533C ancestor from Spain (Catalunia region) who migrated to Southeastern Brazil in the late 1800s (Cunha et al. 2017).

Two Greek p.G533C families also were identified in Southern Central Greece and the Peloponnese. Remarkably, p.G533C carriers from Greece were distantly related to the Spanish p.G533C ancestor who migrated to Southeastern Brazil in the late 1800s (Cunha et al. 2017).

In Europe, most RET variants seemingly are distributed more or less evenly across countries (Machens et al. 2009). Although national screening programs and case ascertainment vary from country to country, distinct RET variants, typically associated with a sporadic appearing, less-aggressive MTC in the fifth and sixth decade of life, are more frequent in some European countries than others based on comparative literature review (Machens et al. 2009):

- p.L790F: $12 \%$ in Germany; $1-4 \%$ in Italy and France; $0 \%$ in Czech Republic and Poland;

- p.Y791F: 0\% in France and Italy; 7\% in Germany; 9\% in Czech Republic; 19\% in Poland;

- p.V804: 4\% in Poland; 6\% in Germany; 15\% in France and $20 \%$ in Italy in which haplotype analysis excluded a founder effect (Romei et al. 2010).

Based on historic settlement areas, these comparative genomic data may hint at a putative 'Germanic' ancestry (RET p.L790F), a putative 'Slavic' ancestry (RET p.Y791F) and a putative 'Roman' ancestry (RET p.V804), subject to further validation. Arguably, such ethnic constructs may simply reflect longstanding inheritance of RET variants created centuries ago in a geographic region.

Twenty-five years into the genomic era, we explored the geographic epidemiology of these three RET variants in present-day Germany in relation to historic Roman and Slavic settlement areas. For the purpose of this study, 'variant' is used as a neutral term regardless of whether current evidence indicates ligand-independent activation of the RET receptor protein, qualifying these variants as mutations (e.g., p.L790F or p.V804M) or no longer (e.g., Y791F). For retrospective analysis of existing data sets from routine patient care, no institutional review board approval is required under German law and applicable institutional regulations.

Kindreds from 209 unrelated families carrying RET variants commonly associated with MEN 2A (Wells et al. 2015) underwent standard MEN 2A-related interventions 
in Germany, chiefly under the care of the senior author (Dralle et al. 1992, Machens et al. 2013a). Retained in the study was one German family with a family branch living in the Netherlands, which resided in a German postal code area adjoining the Dutch border. Twenty RET families, originating from outside of Germany, were excluded: 5 from Turkey; 3 each from Italy and Romania; 2 each from Austria and Cyprus and 1 each from Albania, Congo, Greece, Russia and the USA. The remaining 189 German RET families, believed to account for more than half of all RET families in Germany (Machens et al. $2013 b$ ) were eligible for exploratory analysis. Table 1 (footnote) provides a detailed breakdown of these 189 German families by all 28 unique RET sequence variants found.

For each German RET family, the last common ancestor with, or alternatively the last common obligate carrier without, positive RET test was identified on pedigree analysis together with the German postal code area of his place of residence. The 95 German postal code regions, encompassing broadly comparable numbers of households, were clustered into a historic Roman $(\sim 200$ AD) settlement area (postal code areas 40, 41, 47, 50, $52-56,60,61,63-69,70-79,80-89,93$ and 94) and a historic Slavic ( $800 \mathrm{AD})$ settlement area (postal code areas $1-4,6-10,12-19,23,39,92,95$ and 96). For evaluation, all postal code regions were dichotomized to yield postal areas reflecting Roman and Slavic historic settlement areas (Fig. 1).

The geographic distributions of RET p.L790F/c.2370G>T, RET p.Y791F and RET p.V804M by historic settlement area are depicted in Fig. 1, which provided the following results on statistical analysis (Table 1):

- RET p.L790F/c.2370G>T (unlike RET p.L790F/c.2370G>C) was more prevalent outside than inside the historic Roman settlement area. This difference became statistically significant only when the control group was modeled closest to the mutational profile ( 10 vs $34 \%$; $P=0.045$ ).

- A significant association was obtained for RET p.Y791F and the Slavic historic settlement area (17\% vs $6 \%$; $P=0.018$ ), which remained statistically significant after modeling the control group closer to the mutational profile.

- A significant association was noted between RET p.V804M (unlike RET p.V804L/c.2410G $>$ T) and the Roman historic settlement area ( $24 \%$ vs $6 \% ; P=0.002)$, which remained statistically significant after modeling the control group closer to the mutational profile.

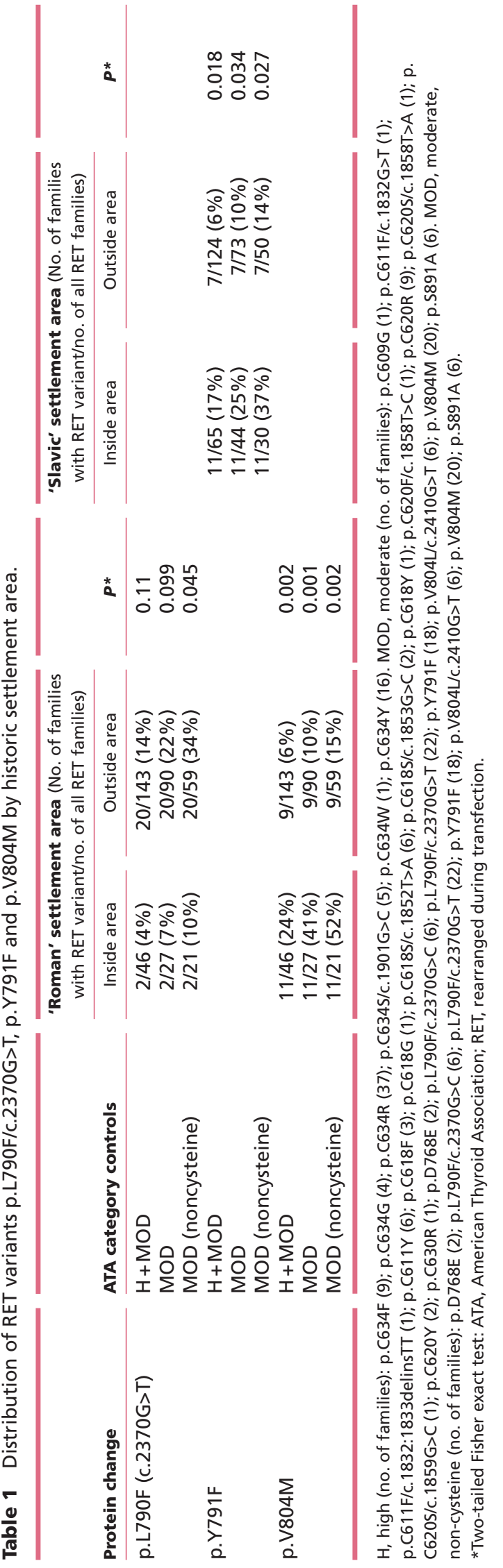

http://erc.endocrinology-journals.org https://doi.org/10.1530/ERC-17-0514

(c) 2018 Society for Endocrinology Published by Bioscientifica Ltd. Printed in Great Britain 
A

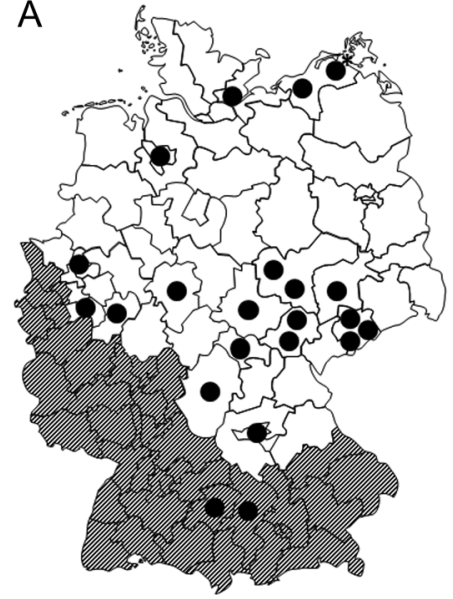

RET p.L790F (c.2410G>A) and 'Roman' Area (shaded)

* recent de novo mutation 1968
B

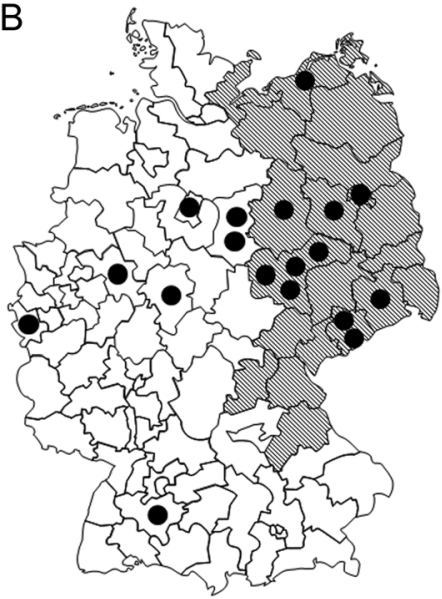

RET pY791F and 'Slavic' Area (shaded)

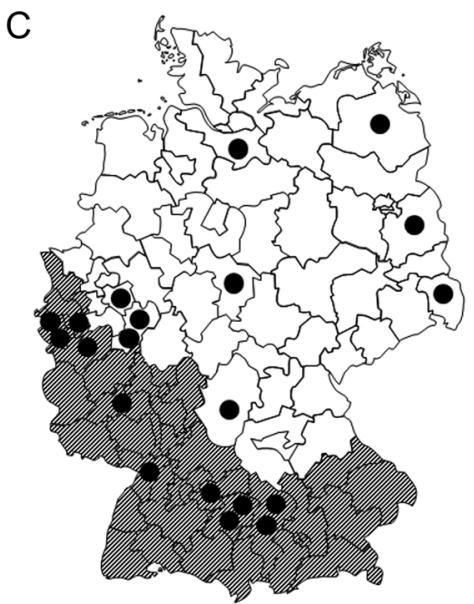

RET p.V804M and 'Roman' Area (shaded)

Figure 1

Distribution by historic settlement areas. (A) RET p.L790F (c.2410G>A) and 'Roman' area (shaded). *recent de novo mutation 1968. (B) RET pY791F and 'Slavic' area (shaded). (C) RET p.V804M and 'Roman' area (shaded).

This geographic epidemiological study lends further credence to comparative evidence from the literature pointing toward a 'Roman' ancestry of RET p.V804M and a 'Slavic' ancestry of RET p.Y791F. For each RET variant, our findings were consistent across all three control groups (Table 1), attesting to the robustness of the association. Owing to limitations in study design, specifically the Germanic ancestral heritage of present-day Germany, our data were inconclusive regarding a putative 'Germanic' ancestry of RET p.L790F/c.2370G $>$ T.

RET screening in Germany has been fully covered by both private and statutory health insurance from inception (Machens et al. 2013b). Even under quasiideal conditions, subjects carrying RET mutations with low transforming activity may not be captured because they do not have pertinent family histories and have not developed MTC. Unless the whole population of a country is screened, which is logistically unfeasible and not cost-effective, under-ascertainment of RET families is inevitable.

Population-based screening, even if instituted now, would not aid much in tracing RET mutations far back in time because at least one parent, grandparent or great-grandparent may have deceased or be unavailable for genomic testing. Because RET p.L790F/c.2370G $>$ T, p.Y791F and p.V804M phenotypes are less penetrant, parents and grandparents who reportedly were free of a disease that was neither suspected nor screened for cannot be assumed not to harbor the trait. Considering our limited data, only two RET mutations in this study came into being more recently: p.L790F/c.2370G $>$ T and C634R. These exceptional instances of de novo mutations were detected on routine screening in two MTC patients born in 1968 and 1983 whose parents each had negative RET gene test results, ruling out longstanding transmission of the trait.

Haplotype analysis may have helped establish relatedness of German families carrying the same RET variant. In Germany, genomic screening raises difficult issues due to German data protection and privacy regulations. Barring unusually fortunate circumstances, it proved challenging to trace mutations back in time over more than four generations, an insurmountable boundary for most ordinary ancestral research.

Misclassification of distantly related RET families as 'unrelated' cannot be ruled out completely but is set to have been non-differential, affecting families carrying the same RET variant and controls equally. Another method to control for variation was calibration of families with the same RET variant against other RET families, using controls modeled closer to the respective mutational profile.

When exploring rare, less penetrant genomic variants such as RET p.L790F/c.2370G >T, p.Y791F and p.V804M, inadequate statistical power always is an issue. First, evidence of absence (negative test result) cannot be taken as absence of evidence (no association). Second, many genetic association studies, http://ercendocrinology-journals.org https://doi.org/10.1530/ERC-17-0514
C) 2018 Society for Endocrinology Published by Bioscientifica Ltd. Printed in Great Britain 
including this one, are somewhat constrained by small sample size and thus have limited statistical power. A statistically significant finding in an underpowered study is more likely to be false positive due to chance than is such a finding in an adequately powered study. In this situation, some researchers may consider correction for multiple testing, although it helps guard against false-positive findings, as too conservative. This is why independent validation of our geographical epidemiological associations remains important. Intriguingly, the association between RET p.V804M and the Roman historic settlement area would have survived correction for multiple testing.

There is a need for additional geographical epidemiological studies, in particular from countries that include historic Germanic settlement areas and have equally comprehensive national RET screening programs. Because the RET p.L790F variant was found in at least 19 families from France (Bihan et al. 2013) and 8 families from Italy (Romei et al. 2010), these countries may be ideally suited to elucidate the European ancestry of the RET L790F variant.

\section{Andreas Machens ${ }^{1}$ Kerstin Lorenz ${ }^{1}$ Frank Weber ${ }^{2}$ Henning Dralle ${ }^{2}$}

${ }^{1}$ Medical Faculty, Department of General, Visceral and Vascular Surgery, Martin Luther University Halle-Wittenberg, Halle, Germany

${ }^{2}$ Department of General, Visceral and Transplantation Surgery, Section of Endocrine Surgery, University of Duisburg-Essen, Essen, Germany

Correspondence should be addressed to A Machens: AndreasMachens@aol.com

\section{Declaration of interest}

The authors declare that there is no conflict of interest that could be perceived as prejudicing the impartiality of this article.

\section{Funding}

This work did not receive any specific grant from any funding agency in the public, commercial or not-for-profit sector.

\section{References}

Bihan H, Murat A, Fysekidis M, Al-Salameh A, Schwartz C, Baudin E, Thieblot P, Borson-Chazot F, Guillausseau PJ, Cardot-Bauters C, et al. 2013 The clinical spectrum of RET proto-oncogene mutations in codon 790. European Journal of Endocrinology 169 271-276. (https:// doi.org/10.1530/EJE-13-0050)

Cunha LL, Lindsey SC, França MI, Sarika L, Papathoma A, Kunii IS, Cerutti JM, Dias-da-Silva MR, Alevizaki M \& Maciel RM 2017 Evidence for the founder effect of RET533 as the common Greek and Brazilian ancestor spreading multiple endocrine neoplasia 2A. European Journal of Endocrinology 176 515-519. (https://doi.org/10.1530/EJE-16-1021)

Dralle H, Scheumann GF, Kotzerke J \& Brabant EG 1992 Surgical management of MEN 2. Recent Results in Cancer Research 125 167-195.

Eng C, Clayton D, Schuffenecker I, Lenoir G, Cote G, Gagel RF, van Amstel HK, Lips CJ, Nishisho I, Takai SI, et al. 1996 The relationship between specific RET proto-oncogene mutations and disease phenotype in multiple endocrine neoplasia type 2. Journal of the American Medical Association 276 1575-1579. (https://doi. org/10.1001/jama.1996.03540190047028)

Machens A, Lorenz K \& Dralle H 2009 Constitutive RET tyrosine kinase activation in hereditary medullary thyroid cancer: clinical opportunities. Journal of Internal Medicine 266 114-125. (https://doi. org/10.1111/j.1365-2796.2009.02113.x)

Machens A, Lorenz K \& Dralle H 2013a Peak incidence of pheochromocytoma and primary hyperparathyroidism in multiple endocrine neoplasia 2: need for age-adjusted biochemical screening. Journal of Clinical Endocrinology and Metabolism 98 E336-E345. (https://doi.org/10.1210/jc.2012-3192)

Machens A, Lorenz K, Sekulla C, Höppner W, Frank-Raue K, Raue F \& Dralle H $2013 b$ Molecular epidemiology of multiple endocrine neoplasia 2: implications for RET screening in the new millenium. European Journal of Endocrinology 168 307-314. (https://doi. org/10.1530/EJE-12-0919)

Martins-Costa MC, Cunha LL, Lindsey SC, Camacho CP, Dotto RP, Furuzawa GK, Sousa MS, Kasamatsu TS, Kunii IS, Martins MM, et al. 2016 M918V RET mutation causes familial medullary thyroid carcinoma: study of 8 affected kindreds. Endocrine-Related Cancer 23 909-920. (https://doi.org/10.1530/ERC-16-0141)

Romei C, Mariotti S, Fugazzola L, Taccaliti A, Pacini F, Opocher G, Mian C, Castellano M, degli Uberti E, Ceccherini I, et al. 2010 Multiple endocrine neoplasia type 2 syndromes (MEN 2): results from the ItaMEN network analysis on the prevalence of different genotypes and phenotypes. European Journal of Endocrinology 163 301-308. (https://doi.org/10.1530/EJE-10-0333)

Wells SA Jr, Asa SL, Dralle H, Elisei R, Evans DB, Gagel RF, Lee N, Machens A, Moley JF, Pacini F, et al. 2015 Revised American Thyroid Association guidelines for the management of medullary thyroid carcinoma. Thyroid 25 567-610. (https://doi.org/10.1089/ thy.2014.0335)

Received in final form 15 January 2018

Accepted 29 January 2018

Accepted Preprint published online 29 January 2018 (c) 2018 Society for Endocrinology Published by Bioscientifica Ltd. Printed in Great Britain 